\title{
Clarifying the Links Among Online Gaming, Internet Use, Drinking Motives, and Online Pornography Use
}

Article · November 2014

DOI: $10.1089 / g 4 h .2014 .0054$

CITATIONS

5

3 authors:

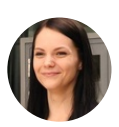

Beáta Bőthe

Eötvös Loránd University

18 PUBLICATIONS 9 CITATIONS

SEE PROFILE

\section{Orosz Gábor}

Hungarian Academy of Sciences

48 PUBLICATIONS 38 CITATIONS

SEE PROFILE
István Tóth-Király

Eötvös Loránd University

20 PUBLICATIONS 10 CITATIONS

SEE PROFILE 


\title{
Dreaming About Online Gaming Triumphs over Watching Online Porn-Clarifying the Links Among Online Gaming, Internet Use, Drinking Motives, and Online Pornography Use
}

\author{
Beáta Bőthe, MS, ${ }^{1,2}$ István Tóth-Király, MS, ${ }^{1,2}$ and Gábor Orosz, $\mathrm{PhD}^{1,3}$
}

\begin{abstract}
Objective: This study was aimed at investigating the links between online gaming and online pornography use by considering gender, problematic Internet use, and different motives for alcohol drinking.

Materials and Methods: University students $(n=512$; mean age, 22.11 years; standard deviation $=2.43$ years; 64.06 percent women) filled in the Cyber Pornography Use Inventory, Hungarian version, the Problematic Online Gaming Questionnaire, Hungarian version (POGQ-HU), the Problematic Internet Use Questionnaire, Hungarian version (PIUQ-HU), and the Drinking Motive Questionnaire Revised Short Form, Hungarian version (DMQ-R-HU SF) questionnaires.

Results: According to hierarchical multiple regression analyses, the neglect factor of PIUQ-HU, the conformity factor of DMQ-R-HU SF, and the immersion and preoccupation factors of POGQ-HU have a significant predictive value on one's online pornography use, but gender does not.

Conclusions: This research shows that independently from the effect of Internet and alcohol use dimensions, immersion and preoccupation factors of online gaming have significant effects on online pornography use. However, preoccupation has a negative effect on pornography use. Players scoring high on this subscale may think about gaming as the only interesting activity that rates higher than even pornography.
\end{abstract}

\section{Introduction}

Online gameplaying

O NLINE GAMEPLAYING IS a widespread activity all over the world, and problematic gaming has a great impact on almost every aspect of the player's life, whereas recreational gaming does not. ${ }^{1}$ According to the "Everquest'" game study, the average online game player is a single 28 -year-old man, who is currently a university student and playing 25 hours per week. ("Everquest" is a massively multiplayer online role-playing game that lets the user to create different types of characters and then explore a virtual world while interacting with the virtual environment and other players as well. ${ }^{2}$ ) However, this is not representative for the whole population because only volunteers participated in this study. ${ }^{3}$ Young men (14-29 years old) spend three times more hours per week on gaming than women. ${ }^{4}$ However, the majority of young adults are not problematic users (only 4.1 percent of them); for the majority of gamers it is a recreational activity. ${ }^{1}$ One of the main motivations of users is escapism $^{5,6}$ : They use online games to avoid thinking about real life (e.g., relationship) difficulties. Problematic users of online games have fewer offline interpersonal relationships than nonproblematic users or those who spend no time playing online games. ${ }^{7}$ However, one-quarter of gamers play with their partner. ${ }^{3}$ Therefore, beside negative effects, online gaming can have positive effects on personal relationships.

In Hungary, $18 \mathrm{Web}$ sites offer playing online games, and the number of registered users is approximately 30,000, but this is a constantly changing number. (There are overlaps between the Web sites because some players use more than one Web site for playing, and some registered gamers have stopped playing games.) The online gamers' average age in Hungary is 21 years, more than 90 percent of them are male, two-thirds of them are single, and only 12 percent live together with their partner. ${ }^{8}$

Many games include sexually explicit materials that can have an effect on the player. Unfortunately, to our best knowledge no research has investigated the relationship between online gaming and online pornography. However,

\footnotetext{
${ }^{1}$ Institute of Psychology, University of Eötvös Loránd, Budapest, Hungary.

${ }^{2}$ Institute of Psychology, University of Szeged, Szeged, Hungary.

${ }^{3}$ MTA Research Centre for Natural Sciences, Institute of Cognitive Neuroscience and Psychology, Budapest, Hungary.
} 
according to Zimbardo and Duncan, ${ }^{9}$ online pornography use and online gaming have a lot in common-They are "arousal addictions": The novelty and the surprise attract people to use them over and over again, and they do not want more of the same thing, unlike in traditional addictions. To the best of our knowledge, no prior study examined the average time one online gamer spends watching online pornography. Supposedly, online gamers spend more time playing games than watching pornography online.

Therefore, we suggest that besides the similar motivational background described by Zimbardo and Duncan? (arousal addiction), we suppose that the time one spends with online gaming can more reliably predict the online pornography use than the reverse. Furthermore, we propose that in order to understand the link between online gaming and online pornography use, it is important to take into consideration further potential variables that can be interpreted also as arousal addictions (e.g., problematic Internet use) in order to measure the unique common variance regarding online gaming addiction and pornography addiction. Finally, we suppose that not only arousal addictions can appear hand in hand; therefore, we intended to take into consideration also one of the most prevalent ${ }^{10}$ "traditional" addictions in Hungary (alcohol). Therefore, in our research, we aimed at investigating the relationships of the factors of online pornography use, the factors of the problematic Internet use, the motives of alcohol use, and the factors of online gaming.

\section{Online pornography}

Online pornography is a controversial topic. Still, it is an important research area because the Internet facilitates the access to adult pages, which are in the list of the Top 500 Sites. ${ }^{11}$ Cooper ${ }^{12}$ identified the notion of "Triple A" (access, affordability, anonymity) regarding the relationship between Internet and online pornography. He claimed that online pornography becomes more and more used because the Internet allows instant access, it is relatively affordable, and it protects an individual's identity through anonymity. An alternative model was developed including anonymity, convenience, and escape (ACE), which differs from "Triple A" regarding such motivational bases as convenience and the above-mentioned escapism. ${ }^{13}$ According to Frangos et al., ${ }^{14}$ pornographic sites have several risk factors for problematic Internet users because these individuals spend more time on the Internet than the average; thus they are endangered to consume more pornographic materials too.

Many studies came to the conclusion that watching pornography is essentially a male activity. ${ }^{15-21}$ According to Mansson, as cited by Daneback et al., ${ }^{22}$ women rarely watch it, and in these cases, they do it with their significant other. Tsitska et al. ${ }^{21}$ mentioned that frequent users of pornographic Internet sites are more likely to access the Web for pornography and gaming. Based on this, we suppose a positive link between Internet use and online pornography use. Furthermore, we suppose a positive link between online gaming and pornography use.

\section{Other addictive activities: Alcohol}

Based on previous studies, ${ }^{14,23,24}$ we suppose that if one participates in an activity that could cause addiction, she or he will be more likely to participate in other addictive activities, such as drinking alcohol. Not only the above-mentioned activ- ities (online pornography and online gaming) could cause addiction, but alcohol consumption could endanger college students as well. A representative study of college students in the United States was conducted in which 44 percent of students were binge drinkers (i.e., men drank five or more and women drank four or more alcoholic drinks in a row ${ }^{24}$ ). We suppose that the motives of alcohol drinking can predict online pornography use because behind both problematic behaviors (online gaming, alcohol drinking), we can identify a couple of similar motives (e.g., escaping from real life problems, coping, social motives). ${ }^{5,6,25}$ Consequently, in the present study we hypothesized that online gaming, Internet use, and different motives of alcohol drinking are positively related to one's pornography use.

\section{Materials and Methods}

\section{Participants}

Five hundred twelve Hungarian university students, of whom 328 (64.06 percent) were women, between 18 and 41 years of age (mean age, 22.11 years; standard devia- correct: tion $=2.43$ years) were recruited for the study. Three hundred mean age $=22.11$ years twenty of the respondents ( 152 women [ 47.50 percent]) had watched online pornography in the last 6 months, 205 of the respondents (103 women [ 50.24 percent]) had been playing online games, and 151 students (52 women [ 34.44 percent]) had watched pornography and had been playing online games as well. On average, the respondents watched online pornography approximately twice a month, and for one occasion, they spent 15-30 minutes with this activity (Table 1).

\section{Procedure}

Our research was conducted with an online questionnaire; filling it out took about 15 minutes. The respondents were recruited on Facebook; the link of the questionnaire was shared in groups of university students. Unfortunately, because of the limitations of the software used, we do not know exactly how many respondents stopped filling out the form before finishing it. First, we informed the participants about the aim of this research and the content of the questionnaire. Their anonymity was assured, and they did not receive compensation for the participation. Then, we asked for some demographic data, such as age, gender, and qualifications of the parents. This section was followed by the Hungarian versions of the Cyber Pornography Use Inventory (CPUIHU), the Drinking Motive Questionnaire Revised Shortened Form (DMQ-R-HU SF), the Problematic Online Gaming Questionnaire (POGQ-HU), and the Problematic Internet Use Questionnaire (PIUQ-HU). Descriptives of the included questionnaires can be seen in Table 1. This study has been approved by the University of Szeged's ethics board.

\section{Measures}

CPUI-HU. We intended to use a questionnaire that could validly and reliably measure one's online pornography consumption. For this purpose, we adapted in Hungarian the Cyber Pornography Use Inventory ${ }^{26}$ in a preliminary study. First, the original 40 items were translated and tested by exploratory factor analysis with principal axis factoring and direct oblimin rotation on a sample of 222 subjects. We wanted to create a shorter version so that respondents could finish it quickly, and a shorter version could be included in a 
Table 1. Descriptive Statistics of the Included Questionnaires

\begin{tabular}{lcccc}
\hline Scales & Score range & "Raw" scores & Mean scores & SD of mean scores \\
\hline CPUI-HU & $12-84$ & 22.03 & 1.84 & 0.88 \\
Compulsivity & $4-28$ & 6.69 & 1.67 & 1.10 \\
Social anxiety & $4-28$ & 9.26 & 2.32 & 1.29 \\
Negative feelings toward viewing online pornography & $4-28$ & 6.08 & 1.52 & 1.07 \\
POGQ-HU & $18-90$ & 35.37 & 1.97 & 0.62 \\
Preoccupation dimension & $2-10$ & 4.19 & 2.09 & 0.94 \\
Immersion dimension & $4-20$ & 11.35 & 2.84 & 1.00 \\
Withdrawal dimension & $4-20$ & 6.36 & 1.59 & 0.71 \\
Overuse dimension & $4-20$ & 5.79 & 1.93 & 0.87 \\
Interpersonal conflicts dimension & $2-10$ & 3.42 & 1.71 & 0.88 \\
Social isolation dimension & $3-15$ & 4.27 & 1.42 & 0.66 \\
PIUQ-HU & $18-90$ & 35.93 & 1.98 & 0.63 \\
Obsession dimension & $6-30$ & 10.41 & 1.72 & 0.69 \\
Neglect dimension & $6-30$ & 12.38 & 2.03 & 0.65 \\
Control disorder dimension & $6-30$ & 13.25 & 2.18 & 0.81 \\
DMQ-R-HU & & & & \\
Social motive & $3-15$ & 9.72 & 3.19 & 1.23 \\
Coping motive & $3-15$ & 5.63 & 1.89 & 1.09 \\
Enhancement motive & $3-15$ & 7.22 & 2.41 & 1.06 \\
Conformity motive & $3-15$ & 4.80 & 1.50 & 0.73 \\
Frequency of online pornography watching & $1-8^{\mathrm{a}}$ & 4.63 & 4.63 & 2.01 \\
Time spent watching online pornography per occasion & $1-6^{\mathrm{b}}$ & 2.76 & 2.76 & 0.97 \\
\hline
\end{tabular}

${ }^{\mathrm{a}}$ On a scale of $1=$ more than once a day; $2=$ daily; $3=$ more than once a week; $4=$ weekly; $5=$ twice a month; $6=$ monthly; $7=$ every few months; and $8=$ a few times a year.

${ }^{b}$ On a scale of $1=$ less than 5 minutes; $2=5-15$ minutes; $3=15-30$ minutes; $4=30-60$ minutes; $5=1-2$ hours; and $6=$ more than 2 hours.

CPUI-HU, Cyber Pornography Use Inventory, Hungarian version; DMQ-R-HU SF, Drinking Motive Questionnaire Revised Short Form, Hungarian version; PIUQ-HU, Problematic Internet Use Questionnaire Hungarian version; POGQ-HU, Problematic Online Gaming Questionnaire, Hungarian version; SD, standard deviation.

larger questionnaire battery easier, as well. For this purpose, three subscales were identified: (a) negativity towards viewing online pornography, (b) compulsivity, and (c) social anxiety. All showed acceptable reliability in terms of internal consistency ( $\alpha=0.88, \alpha=0.80$, and $\alpha=0.72$, respectively). The overall Cronbach $\alpha$ value was 0.84 for the questionnaire.

For the present study, confirmatory factor analysis was performed (maximum likelihood estimation, first-order model with one error covariance) on the basis of the exploratory factor analysis results of the preliminary study. The final model including 12 items, and three factors had tolerable model fit $(\mathrm{CMIN} / \mathrm{DF}=3.42 ; \mathrm{GFI}=0.92 ; \mathrm{CFI}=0.93 ; \mathrm{TLI}=$ 0.91 ; root mean square error of approximation $=0.08$ ), similar to the more recent short version of Grubbs et al. ${ }^{27}$ Their new version consists of nine items and three factors (compulsivity, efforts, and distress), similar to the Hungarian short version.

Negativity toward viewing online pornography indicates one's negative emotions toward this activity. The second factor is compulsivity, which assesses the compulsive behaviors and feelings that one might have regarding online pornography. High scores on this subscale indicate an existing problem that roots in pornography and could hinder everyday functioning. The third factor is social anxiety, which refers to the negative emotions regarding the possibility of someone uncovering one's secret activity. More secrecy means higher levels of anxiety that could also have a negative effect on life.

POGQ-HU. The 18-item questionnaire was created and validated in Hungarian by Demetrovics et al. ${ }^{28}$ It contains six subscales: Overuse (three items) refers to elongated gaming time and difficulties in controlling the time spent on gaming; preoccupation (two items) refers to daydreaming and obsessive thinking about online gaming; social isolation (three items) refers to preference of gaming over social relationships and activities; interpersonal conflicts (two items) refer to conflicts and comments on the player's overuse; immersion (four items) refers to losing track of time and dealing excessively with games; and the last dimension, withdrawal (four items), refers to withdrawals in cases when gamers experience difficulties in playing. The respondents have to rate each item using a 5-point Likert scale (from $1=$ never to $5=$ almost always/always). For this sample, the reliability in terms of internal consistency was perfect $(\alpha=0.90)$.

PIUQ-HU. Demetrovics et al. ${ }^{28}$ created a Hungarian, 18item questionnaire that can indicate problematic Internet use. It consists of three subscales, each of which contains six items: obsession, neglect, and control disorder. The obsession subscale refers to daydreaming about the Internet and anxiety when the individual cannot connect to the Web. The second subscale-neglect-refers to the neglecting of everyday activities like eating, studying, or working. The last factor of the model is control disorder, in which people use the Internet more than they planned in advance. The respondents have to rate each item using a 5-point Likert scale (from $1=$ never to $5=$ almost always/always). For this sample, the reliability in terms of internal consistency was high $(\alpha=0.90)$.

DMQ-R-HU SF. The original Drinking Motives Questionnaire ${ }^{29}$ contains 20 items in four factors, and the respondents 
have to rate each item using a 6-point Likert scale (from $0=$ never to $5=$ almost always). The questionnaire was validated on a high school and college student sample in Hungary. ${ }^{25}$ The short form of the questionnaire ${ }^{30}$ contains 12 items. Both the short and the long versions measure with high validity and reliability in the same for motives (factors) for alcohol use. The first factor, (a) enhancement, refers to drinking to feel more pleasurable inner experiences. The second factor, (b) social motive, refers to boosting the enjoyment of social interactions. The third factor, (c) conformity, refers to the motive of drinking because we do not want to be an outcast. The fourth factor, (d) coping, refers to the avoidance of the negative inner conditions. The respondents have to rate each item using a 5-point Likert scale (from $1=$ almost never/never to $5=$ almost always/always). It was validated on a Hungarian young adult sample. ${ }^{25}$ As for drinking motives, there were only measureable Cronbach $\alpha$ values because the motives were not summable $\left(\alpha_{\text {enhancement motive }}=0.65 ; \alpha_{\text {social motive }}=0.89 ; \alpha_{\text {conformity motive }}=\right.$ $0.81 ; \alpha_{\text {coping motives }}=0.90$ ).

\section{Statistical analyses}

The statistical analyses were performed by SPSS version 15 software and AMOS version 17 software (SPSS, Inc., Chicago, IL). Correlations were evaluated by the Pearson coefficient $r$. Hierarchical multiple regression was performed to investigate the effects of the independent variables on problematic pornography use. Moreover, exploratory factor analysis and confirmatory factor analysis were performed to investigate the factor structure of the Hungarian version of the CPUI-HU version.

\section{Results}

\section{Regression analysis}

Hierarchical multiple regression analysis was performed in order to investigate the effect of (a) problematic Internet use, (b) problematic online gaming, and (c) different alcohol drinking motivations on problematic pornography use, after controlling for gender. (Preliminary analyses were performed to check whether multicollinearity exists among the variables. All correlations were weak to moderate; only the two variables related to gaming had showed high correlation $\left[r_{149}=0.54, P<0.01\right]$. Therefore these two were entered into the same block to avoid violation of the analysis.) The hierarchical regression analysis consisted of four steps.

In the first step, the predictor of gender $(0=$ women, $1=$ men) was entered as a dummy variable based on previous research. ${ }^{15-21}$ This model was statistically significant $\left(F_{1,318}=10.83 ; P<0.001\right)$, and it explained 3.3 percent of the variance of problematic pornography use (Table 2). These results mean that men use more pornography than women.

In step 2, the neglect dimension of PIUQ-HU was entered, and it was also statistically significant $\left(F_{1,317}=56.46 ; P<\right.$ 0.001 ), and it explained 14.6 percent of the dependent variable, raising the total variance to 17.9 percent. In the next step, the conformity factor of the DMQ-R-HU SF was included, which was also statistically significant $\left(F_{1,314}=9.31\right.$; $P<0.002)$, increasing the total variance explained to 20.4 percent.

Finally, in step 4, the preoccupation and the immersion factors of the online gaming questionnaire were entered, raising the level of the variance to 21.5 percent, which was a significant level $\left(F_{2,143}=3.90 ; P<0.02\right)$. In this final model, out of the five variables, four remained significant: (a) the neglect factor of the PIUQ-HU had the highest $\beta$ value ( $\beta=0.31, P<0.001)$, and (b) the conformity of the alcohol motivation scale had the second highest $\beta$ value $(\beta=0.23$, $P<0.006)$. The last two significant predictors were factors of the POGQ-HU: (c) immersion $(\beta=0.20, P<0.026)$ and (d) preoccupation $(\beta=-0.24, P<0.011)$, whereas gender turned out to be an insignificant predictor. (Changing the order of the blocks results in negligible differences in terms of explain variance change or standardized $\beta$ values.)

Table 2. Hierarchical Regression Model of Problematic Pornography Use

\begin{tabular}{|c|c|c|c|c|c|c|c|}
\hline & $\mathrm{R}$ & $\mathrm{R}^{2}$ & $\mathrm{R}^{2}$ change & $B$ & $S E$ & $\beta$ & $\mathrm{t}$ \\
\hline $\begin{array}{l}\text { Step } 1 \\
\text { Gender }\end{array}$ & 0.18 & 0.03 & 0.03 & 0.97 & 0.29 & $0.18^{\mathrm{a}}$ & 3.29 \\
\hline $\begin{array}{l}\text { Step } 2 \\
\quad \text { Gender } \\
\text { PIUQ-HU neglect }\end{array}$ & 0.42 & 0.18 & 0.15 & $\begin{array}{l}0.82 \\
0.26\end{array}$ & $\begin{array}{l}0.27 \\
0.03\end{array}$ & $\begin{array}{l}0.15^{\mathrm{b}} \\
0.38^{\mathrm{a}}\end{array}$ & $\begin{array}{l}3.01 \\
7.51\end{array}$ \\
\hline $\begin{array}{l}\text { Step } 3 \\
\text { Gender } \\
\text { PIUQ-HU neglect } \\
\text { DMQ-R-HU conformity }\end{array}$ & 0.45 & 0.20 & 0.02 & $\begin{array}{l}0.75 \\
0.22 \\
0.53\end{array}$ & $\begin{array}{l}0.27 \\
0.04 \\
0.17\end{array}$ & $\begin{array}{l}0.14^{\mathrm{b}} \\
0.32^{\mathrm{a}} \\
0.17^{\mathrm{b}}\end{array}$ & $\begin{array}{l}2.78 \\
5.89 \\
3.05\end{array}$ \\
\hline $\begin{array}{l}\text { Step } 4 \\
\text { Gender } \\
\text { PIUQ-HU neglect } \\
\text { DMQ-R-HU conformity } \\
\text { POGQ-HU immersion } \\
\text { POGQ-HU preoccupation }\end{array}$ & 0.46 & 0.21 & 0.04 & $\begin{array}{r}0.50 \\
0.23 \\
0.81 \\
0.13 \\
-0.34\end{array}$ & $\begin{array}{l}0.42 \\
0.06 \\
0.29 \\
0.06 \\
0.13\end{array}$ & $\begin{array}{r}0.09 \\
0.31^{\mathrm{a}} \\
0.23^{\mathrm{b}} \\
0.20^{\mathrm{c}} \\
-0.24^{\mathrm{b}}\end{array}$ & $\begin{array}{r}1.20 \\
3.75 \\
2.78 \\
2.25 \\
-2.57\end{array}$ \\
\hline
\end{tabular}

Statistical significance: ${ }^{\mathrm{a}} P<0.001,{ }^{\mathrm{b}} P<0.01,{ }^{\mathrm{c}} P<0.05$.

DMQ-R-HU conformity, Drinking Motive Questionnaire Revised Short Form, Hungarian version, conformity motive; PIUQ-HU neglect, Problematic Internet Use Questionnaire, Hungarian version, neglect dimension; POGQ-HU immersion, Problematic Online Gaming Questionnaire, Hungarian version, immersion dimension; POGQ-HU preoccupation, Problematic Online Gaming Questionnaire, Hungarian version, preoccupation dimension. 


\section{Discussion}

Online questionnaire responses from Hungarian respondents were used in order to measure the links between problematic online gaming and problematic pornography use by considering problematic Internet use and different motives of alcohol drinking. Our results indicate that certain factors have an effect on someone's attitudes toward pornography. Among these factors, the neglect factor of the Internet questionnaire has the strongest effect, which supports the previous results of Frangos et al., ${ }^{14}$ who mentioned that problematic Internet users could consume more online pornography based on the fact that they are always trying to be online, neglecting their duties.

Besides neglect, two other online gaming factors were included in this model (immersion and preoccupation) that also had significant predictive effects. The former refers to someone who loses track of time because he or she is constantly playing with online games, and the positive link in the final model indicates that the same can happen with pornography. Deep immersion in online games is hand in hand with deep immersion in online pornography. However, the preoccupation factor of online gaming is negatively linked to problematic pornography use. It can be interpreted as daydreaming about online gaming or obsession toward it might suppress inclination in the use of online pornography. Therefore, we propose that the higher a player scores on the preoccupation online gaming scale (the more he or she thinks about gaming), the lower his or her interest toward other activities will be, such as pornography. (However, we must mention that we have data only regarding overuse, but we have no precise data about the time respondents spend with online gaming. Furthermore, we have data about motivation of alcohol use and the frequency of alcohol use, but we have no data regarding the quantity of the consumed alcohol.) By examining these motivational factors, we can conclude that thinking and daydreaming about one problematic online activity (online gaming) might override the motivation toward another similar online activity (pornography use). Another very simple explanation of this link is that daydreaming about online gaming can appear in the absence of Internet access, which can prevent the individual from watching online pornography. Further examination is needed to explore the effect of preoccupation factor of the gamers' behavior when one has the possibility to play versus in the case when one has not.

Previous studies ${ }^{14,23,24}$ also mentioned that participation in a potentially addictive activity could lead to participation in other ones. Our results correspond with these findings because not just problematic online gaming and problematic Internet use are related to problematic pornography use, but the motivations for drinking alcohol as well. Namely, the conformity factor of this questionnaire also explained the variance of pornography use, which not only strengthens the already mentioned hypothesis, but raises the question whether actual conformity plays a role in the phenomenon. However, further research is needed to explore how group conformity can be related to pornography use.

Based on the work of Zimbardo and Duncan, ${ }^{9}$ arousal addictions differ from traditional ones in that in the case of the latter (e.g., alcohol), the user wants the same thing over and over again, whereas in the case of the former (e.g., gaming or online pornography), the novelty and the new, undiscovered components are the ones that captivate the user. Here lies the importance of this research: Nowadays, people need more and more stimulation, more and more new experience. And how are young adults to satisfy this need for stimulation? They search for means that are legal, relatively cheap, and easily accessible and leave no visible markers (for instance, there are external signs if someone has problems with alcohol or drugs), like online gaming and porn.

It is important to note that like other studies, this one also has limitations. First, we must mention that it is a single crosssectional, correlational analysis. Inferences about causation cannot even be even attempted. Respondents had to answer through the Internet, which can always raise questions about the real identity of the respondent. We have no information about the incompletion rate. These measures, despite their psychometric appropriateness, assess how problematic a respondent believes or perceives his or her behavior to be, and not actual consequences of the behaviors of the respondents. It is possible also that those individuals who perceive their gaming behavior as problematic may perceive their pornographic use as problematic, even if there is no objective evidence for it. Regarding the CPUI-HU, further psychometric investigations are needed. Respondents could have been asked about their time actually spent with gaming, which could have proved to be an additional method in the interpretation of online gaming. Although students of different institutions have participated in this research, representativeness should be increased in future studies with more diverse samples. This study only surveys people who watch pornography on the Internet. It could be insightful if non-watcher gamers participate as well.

\section{Acknowledgments}

This research was supported in part by a grant from the Hungarian Research Fund: The Role of Individual Differences and Situative Factors in Skill Learning (PD 106027) (Project Leader: G.O.).

\section{Author Disclosure Statement}

No competing financial interests exist.

\section{References}

1. Mentzoni RA, Brunborg GS, Molde H, et al. Problematic video game use: Estimated prevalence and associations with mental and physical health. Cyberpsychol Behav Soc Netw 2011; 14:591-596.

2. Chappell D, Eatough V, Davies MNO, Griffiths M. EverQuest-It's just a computer game right? An interpretative phenomenological analysis of online gaming addiction. Int J Ment Health Addict 2006; 4:205-216.

3. Griffiths MD, Davies MN, Chappell D. Demographic factors and playing variables in online computer gaming. Cyberpsychol Behav Soc Netw 2004; 7:479-487.

4. Haagsma MC, Pieterse ME, Peters O. The prevalence of problematic video gamers in the Netherlands. Cyberpsychol Behav Soc Netw 2012; 15:162-168.

5. Demetrovics Zs, Urban R, Nagygyorgy K, et al. Why do you play? The development of the Motives for Online Gaming Questionnaire (MOGQ). Behav Res Methods 2011; 43:814-825. 
6. Yee N. Motivations for play in online games. Cyberpsychol Behav Soc Netw 2006; 9:772-775.

7. Lo SK, Wang CC, Fang W. Physical interpersonal relationships and social anxiety among online game players. Cyberpsychol Behav Soc Netw 2005; 8:15-20.

8. Nagygyorgy K, Urban R, Farkas J, et al. Typology and sociodemographic characteristics of massively multiplayer online game players. Int J Hum Comput Int 2013; 9:192-200.

9. Zimbardo P, Duncan N. The Demise of Guys': How Video Games and Porn Are Ruining a Generation. 2012. http:// edition.cnn.com/2012/05/23/health/living-well/demise-ofguys/ (accessed July 9, 2014).

10. World Health Organization. Global Status Report on Alcohol and Health. 2011. www.who.int/substance_abuse/ publications/global_alcohol_report/msbgsruprofiles.pdf (accessed July 9, 2014).

11. Alexa.com. The Top 500 Sites on the Web. 1996-2014. www.alexa.com/topsites/ (accessed March 24, 2014).

12. Cooper A. Sexuality and the Internet: Surfing into the new millennium. Cyberpsychol Behav 1998; 1:187-193.

13. Young K, Pistner M, O'Mara J, Buchanan J. Cyber disorders: The mental health concern for the new millennium. Cyberpsychol Behav 1999; 2:475-479.

14. Frangos CC, Frangos CC, Sotiropoulos I. Problematic Internet use among Greek university students: An ordinal logistic regression with risk factors of negative psychological beliefs, pornographic sites, and online games. $\mathrm{Cy}$ berpsychol Behav Soc Netw 2011; 14:51-58.

15. Bridges AJ, Morokoff PJ. Sexual media use and relational satisfaction in heterosexual couples. Pers Relationships 2011; 18:562-585.

16. Haggstrom-Nordin E, Hanson U, Tyden T. Associations between pornography consumption and sexual practices among adolescents in Sweden. Int J STD AIDS 2005; 16:102-107.

17. Poulsen FO, Busby DM, Galovan AM. Pornography use: Who uses it and how it is associated with couple outcomes. J Sex Res 2013; 50:72-83.

18. Stack S, Wasserman I, Kern R. Adult social bonds and use of Internet pornography. Soc Sci Q 2004; 85:75-88.

19. Svedin CG, Akerman I, Priebe G. Frequent users of pornography. A population based epidemiological study of Swedish male adolescents. J Adolesc 2011; 34:779-788.

20. Traeen B, Nilsen TS, Stigum H. Use of pornography in traditional media and on the Internet in Norway. J Sex Res 2006; 43:245-254.
21. Tsitsika A, Critselis E, Kormas G, et al. Adolescent pornographic Internet site use: A multivariate regression analysis of the predictive factors of use and psychosocial implications. Cyberpsychol Behav 2009; 12:545-550.

22. Daneback K, Traeen B, Mansson S-A. Use of pornography in a random sample of Norwegian heterosexual couples. Arch Sex Behav 2007; 38:746-753.

23. Ko C, Yen J, Yen C, et al. The association between Internet addiction and problematic alcohol use in adolescents: The problem behavior model. Cyberpsychol Behav 2008; 11: 571-576.

24. Wechsler H, Dowdall GW, Davenport A, Castillo S. Correlates of college student binge drinking. Am J Public Health 1995; 85:921-926.

25. Nemeth Zs, Urban R, Farkas J, et al. Az alkoholfogyasztás motivációi módosított kérdőív hosszú és rövid változatának hazai alkalmazása. Magy Pszichol Szle 2012; 67:673694.

26. Grubbs JB, Sessoms J, Wheeler DM, Volk F. The CyberPornography Use Inventory: The development of a new assessment instrument. Sex Addict Compulsivity 2010; 17: 106-126.

27. Grubbs JB, Volk F, Exline JJ, Pargament KI. Internet pornography use: Perceived addiction, psychological distress, and the validation of a brief measure. J Sex Marital Ther 2013 October 28 [Epub ahead of print]. doi: 10.1080/ 0092623X.2013.842192.

28. Demetrovics Zs, Urban R, Nagygyorgy K, et al. The development of the Problematic Online Gaming Questionnaire (POGQ). PLoS One 2012; 7:e36417.

29. Cooper ML. Motivations for alcohol use among adolescents. Psychol Assess 1994; 6:117-128.

30. Kuntsche E, Kuntsche S. Development and validation of the Drinking Motive Questionnaire Revised Short Form (DMQ-R-SF). J Clin Child Adolesc Psychol 2009; 38:899_ $\underline{908 .}$

Address correspondence to:

Gábor Orosz, PhD

Institute of Cognitive Neuroscience and Psychology MTA Research Centre for Natural Sciences 1394 Budapest, Pf. 398, Hungary

E-mail: orosz.gabor@ttk.mta.hu 